\title{
Associations of meeting 24-h movement guidelines with stress and self-rated health among adults: is meeting more guidelines associated with greater benefits?
}

\author{
Kaja Kastelic ${ }^{1,2}$,̌̌eljko Pedišić ${ }^{3}$, Dean Lipovac ${ }^{1,2}$, Nika Kastelic ${ }^{4}$, Si-Tong Chen ${ }^{3}$ and Nejc Šarabon ${ }^{2,5^{*}}$
}

\begin{abstract}
Background: Several countries have recently issued 24-h movement guidelines that include quantitative recommendations for moderate-to-vigorous physical activity (MVPA), sedentary behaviour (SB), and sleep. This study explored the associations of meeting the 24-h movement guidelines with stress and self-rated health among adults, and whether the likelihood of favourable outcomes increases with the number of guidelines met.

Methods: A total of 2476 adults aged 18 years and over completed a questionnaire on their time spent in MVPA, SB and sleep, frequency of stress (never, very rarely, occasionally, often, every day), self-rated health (very good, good, fair, bad, very bad), sociodemographic characteristics, and lifestyle variables.

Results: In an ordinal logistic regression analysis adjusted for age, sex, body mass index, education, socio-economic status, employment, place of residence, living with or without partner, and smoking, lower odds of higher frequency of stress were found for those meeting the combined 24-h movement guidelines (adjusted odds ratio $[O R]=0.45 ; 95 \%$ confidence interval $[C l]: 0.32,0.63 ; p<0.001$ ), any combination of two guidelines (OR range: $0.48-$ $0.63 ; p<0.05$ for all), and sleep guideline only ( $\mathrm{OR}=0.51 ; 95 \% \mathrm{Cl}: 0.35,0.75 ; p=0.001)$. Higher odds of better selfrated health were found for those meeting the combined 24-h movement guidelines (OR $=2.94 ; 95 \% \mathrm{Cl}: 2.07,4.19$; $p<0.001)$, combination of MVPA and SB guidelines (OR $=2.33 ; 95 \% \mathrm{Cl}: 1.57,3.44 ; p<0.001)$, combination of MVPA and sleep guidelines (OR $=1.78 ; 95 \% \mathrm{Cl}: 1.23,2.59 ; p=0.002)$, and MVPA guideline only (OR $=2.24 ; 95 \% \mathrm{Cl}: 1.50,3.36$; $p<0.001$ ). Meeting more guidelines was associated with greater odds of favourable outcomes ( $p$ for linear trend $<$ $0.001)$

Conclusion: Adults who meet the sleep guideline, any combination of two guidelines, or all three guidelines experience stress less frequently. Meeting the MVPA guideline alone or in combination with any other movement behaviour guideline was associated with better self-rated health. The likelihood of less frequent stress and better self-rated health increases with the number of guidelines met. Adults should be encouraged to meet as many movement behaviour guidelines as possible.
\end{abstract}

Keywords: Subjective health, Well-being, Time-use epidemiology, Daily Activity Behaviours Questionnaire

* Correspondence: nejc.sarabon@fvz.upr.si

${ }^{2}$ InnoRenew CoE, Izola, Slovenia

${ }^{5}$ University of Primorska, Faculty of Health Sciences, Izola, Slovenia

Full list of author information is available at the end of the article

(c) The Author(s). 2021 Open Access This article is licensed under a Creative Commons Attribution 4.0 International License, which permits use, sharing, adaptation, distribution and reproduction in any medium or format, as long as you give appropriate credit to the original author(s) and the source, provide a link to the Creative Commons licence, and indicate if changes were made. The images or other third party material in this article are included in the article's Creative Commons licence, unless indicated otherwise in a credit line to the material. If material is not included in the article's Creative Commons licence and your intended use is not permitted by statutory regulation or exceeds the permitted use, you will need to obtain permission directly from the copyright holder. To view a copy of this licence, visit http://creativecommons.org/licenses/by/4.0/ The Creative Commons Public Domain Dedication waiver (http://creativecommons.org/publicdomain/zero/1.0/) applies to the data made available in this article, unless otherwise stated in a credit line to the data. 


\section{Background}

There has been a recent shift from studying the effects of sleep, sedentary behaviour (SB), and physical activity (i.e. movement behaviours) separately to simultaneously examining the effects of all movement behaviours that occur in a 24-h day [1-6]. This paradigm was motivated by the findings that sleep, SB, and physical activity are associated with health $[7,8]$, and that the amounts of time spent in these behaviours are perfectly collinear parts of the 24-h day - more time spent in one movement behaviour inevitably leads to less time spent in the remaining ones. The new paradigm has been widely accepted by researchers and international and national public health authorities. The World Health Organization and several countries have issued 24-h movement guidelines [9-18]. According to the novel 24h movement guidelines, adults should, for example, limit their SB to no more than eight hours per day, accumulate at least $150 \mathrm{~min}$ of moderate-to-vigorous physical activity (MVPA) per week, and sleep seven to nine hours a day [12].

Studies among children and youth have suggested that adhering to recommendations for a higher number of individual movement behaviours (e.g. for 3 vs for 2, or for 2 vs for 1) is associated with greater health benefits [19, 20]. However, for adult populations, such evidence is scarce. Given that the 24-h movement guidelines for adults have recently been issued in several countries, from a public health perspective it is important to explore whether meeting more movement behaviour guidelines is associated with greater benefits. According to the framework for Viable Integrative Research in Time-Use Epidemiology (VIRTUE), such associations should be explored for a range of health outcomes [2]. For the purpose of this study, we selected stress and self-rated health as outcome variables, as they have often been explored in relation to movement behaviours.

Stress is commonly defined as a "physical, mental, or emotional strain or tension" [21]. It can be understood as individual's response to events that they experience as threatening to their well-being or overwhelming [22]. Although it is a natural response, prolonged stress can have negative effects on health [23]. Chronic stress can substantially alter nervous, cardiovascular, endocrine, and immune functioning, and it is associated with various chronic diseases, including coronary heart disease, stroke, depression, and anxiety [24-28]. Frequent experience of stress is a pervasive issue: every third adult globally reports experiencing a lot of stress [29]. Furthermore, stress is associated with movement behaviours [30-32]. The relationship is considered to be bidirectional, with stress as a predictor of engagement in movement behaviours and engagement in movement behaviours as a predictor of stress. In particular, high stress seems to be associated with low levels of MVPA [32] and short sleep [31]. Findings on the association between SB and stress are inconsistent [33].

Self-rated health is one of the most widely used measures in epidemiological studies [34]. It represents one's subjective evaluation of their own overall health status. Self-rated health is a strong predictor of mortality risk [35], and it was found to be consistent with the objective general health status [36]. Findings from the World Health Survey suggested that the global prevalence of poor self-rated health is around 10\% [37]. Previous studies have found that high MVPA [38], low SB [39] and adequate sleep duration [40] are associated with better self-rated health. These relationships are also likely to be bidirectional [41].

Very few studies examined the associations of the 24-h movement behaviour composition with stress and selfrated health [7, 8, 42]. Previous studies that assessed combinations of movement behaviours in relation to stress have shown mixed findings. For example, Onodera et al. [43] found that reallocating time from SB to MVPA is associated with less stress. Oftedal et al. [44, 45] found a favourable association with stress for an overall 'healthy' combination of movement behaviours (i.e. sufficient MVPA, low SB, and sufficient sleep) and dietary habits. Some studies did not find a significant association between stress and movement behaviour compositions [46, 47]. Furthermore, studies on the association between movement behaviour composition and self-rated health suggested a positive role of MVPA [48] and light-intensity physical activity [47]. However, evidence on the association of adherence to the 24-h movement guidelines with self-rated health and stress is scarce.

Therefore, the aim of this study was to explore the associations of meeting the 24-h movement guidelines with self-rated health and the frequency of stress among adults aged 18 years and over. We focused on exploring whether the likelihood of favourable stress and self-rated health outcomes increases with the number of movement guidelines met. We hypothesised that meeting the combined 24-h movement guidelines (i.e. recommendations for sleep, SB, and MVPA) is associated with better self-rated health and lower frequency of experiencing stress. We also hypothesised that adhering to a higher number of individual recommendations is favourably associated with self-rated health and stress.

\section{Methods}

\section{Data collection and participants}

Data were collected among Slovenian residents aged 18 years and over (including young adults, middle-aged adults, and older adults) from November 2019 to March 2020 using an online survey. Participants were recruited 
via mailing lists, daily newspapers, web-portals, and social media. The participation in the survey was voluntary and anonymous. All participants provided informed consent before commencing with the survey. The study was performed in accordance with the Declaration of Helsinki and it was approved by the Republic of Slovenia National Medical Ethics Committee (approval number: 0120-557/2017/4).

A total of 2476 participants agreed to participate in the study and completed the survey. The survey data were cleaned based automated detection of participants who did not use web-based sliders for responding to specific questions (which indicated that they did not understand how to respond to these questions or did not want to respond). This led to exclusion of 55 participants. Additionally, 88 participants were excluded from this analysis, because they were under the age of 18 years $(n=5)$, they did not provide information on sociodemographic characteristics $(n=55)$, or they provided unrealistic responses on body weight $(n=3)$, and sleep time $(n=25)$. A higher proportion of excluded participants were less educated and unemployed than included participants. We found no significant differences between the excluded participants and the study sample in any other socio-demographic or lifestyle characteristic (data not shown). Data from 2333 participants were included in the final analysis.

\section{Measures}

\section{Movement behaviours}

The amounts of time spent in MVPA, SB, and sleep were assessed using the Daily Activity Behaviours Questionnaire (DABQ) [49]. This 31-item questionnaire asks about MVPA and SB (in the work, transport, domestic, and leisure-time domains) and sleep in the past 7 days. According to Landis and Koch [50], the test-retest reliability of DABQ estimates is moderate (quadratic weighted Cohen's kappa $\left[\kappa_{\mathrm{w}}\right]=0.58$ for sleep, $\kappa_{\mathrm{w}}=0.56$ for $\mathrm{SB}$, and $\kappa_{\mathrm{w}}=0.47$ for MVPA), the agreement of sleep estimates from $\mathrm{DABQ}$ and a time-use diary is substantial $\left(\kappa_{\mathrm{w}}=0.66\right)$, and the agreement between DABQ and accelerometer-inclinometer estimates is moderate for SB $\left(\kappa_{\mathrm{w}}=0.41\right)$ and fair for MVPA $\left(\kappa_{\mathrm{w}}=0.32\right)$.

Based on their responses to DABQ, participants were categorised into the following eight groups: 1) meeting all 24-h movement guidelines; 2) meeting sleep and MVPA recommendations; 3) meeting sleep and SB recommendations; 4) meeting MVPA and SB recommendations; 5) meeting only sleep recommendation; 6) meeting only SB recommendation; 7) meeting only MVPA recommendation; and 8) not meeting any of the recommendations. The thresholds for meeting the recommendations were: at least $150 \mathrm{~min}$ of MVPA per week; less than eight hours of SB per day; and sleeping between seven and nine hours (7:00-9:59 h:mm) per day for adults and between seven and eight hours (7:00-8: $59 \mathrm{~h}: \mathrm{mm}$ ) per day for older adults [12].

\section{Outcomes}

The outcome measures were self-rated health and frequency of stress. The question about stress was: "How often do you feel tense, under stress, or great pressure?" with the following response options: never, very rarely, occasionally, often, and every day [51]. The test-retest reliability of the stress frequency estimate is substantial $\left(\kappa_{\mathrm{w}}=0.77\right)$ [50]. The question about self-rated health was: "In general, how would you rate your current health status?" with the following response options: very good, good, fair, bad, and very bad. The question has been validated before [36], showing a strong association with objectively assessed general health status, morbidity [52], and mortality [35] in the general population. Also, testretest reliability was shown to be good-to-excellent [53].

\section{Socio-demographic and lifestyle characteristics}

We assessed age (continuous variable), sex, body mass index (BMI; calculated from self-reported body height and body weight, and categorised as underweight or 'normal' weight $\left[<25 \mathrm{~kg} / \mathrm{m}^{2}\right]$ / overweight $\left[25.0 \mathrm{~kg} / \mathrm{m}^{2}\right.$ to $\left.29.9 \mathrm{~kg} / \mathrm{m}^{2}\right]$ / obese $\left.\left[\geq 30 \mathrm{~kg} / \mathrm{m}^{2}\right]\right)$, level of education (using the question "What is your highest completed level of education?", with the response options: primary education, vocational secondary education, professional or general secondary education, short-term higher education, and professional or academic higher education that were later grouped into primary or secondary education / higher education), self-perceived socio-economic status (using the question "How would you rate your socioeconomic status?", with the response options: very high, high, middle, low, and very low that were later grouped into high or very high / middle / low or very low), employment status (using the question "Which option below best describe your working status/schedule?", with the response options: employed in non-shift work, employed in shift work that includes only daytime shifts, employed in shift work that includes also night shifts, and unemployed that were later grouped into employed in non-shift work / employed in shift work / unemployed), place of residence (using the question "Do you live in urban or rural area?", with the response options: urban area, and rural area), living arrangement (using the question "Do you reside with spouse/partner?", with the response options: with partner, and without partner) and smoking status (using the question "Do you smoke or using oral tobacco?", with the response options: yes - smoking every day, yes - smoking occasionally, no - never smoked, and no - quit smoking that were later grouped into not smoking / smoking). 


\section{Statistical analysis}

The data were processed and analysed using $\mathrm{R}$ version 4.0.2 [54] and R Studio 1.3.959 [55] with the packages dplyr [56], ggplot2 [57], janitor [58], skimr [59], rstatix [60], MASS [61], brant [62], and generalhoslem [63]. Absolute and relative frequencies (\%) were calculated for all variables.

The associations of meeting the movement guidelines with stress and self-rated health were analysed using ordinal logistic regression (proportional odds) models with stress and self-rated health as outcome variables. The analyses were adjusted for all the above-mentioned socio-demographic and lifestyle variables and for selfrated health (in the analysis with stress as the outcome variable) or stress (in the analysis with self-rated health as the outcome variable). The adjustments for confounding were based on findings of previous studies [64-70].

To examine if the likelihood of favourable stress and self-rated health outcomes increases with the number of movement guidelines met, we ran additional regression models. In these models, the explanatory variable was an ordered factor denoting the number of movement guidelines met (i.e. none, one, two, or all three). We tested for linear and quadratic trends between the explanatory variable (the number of movement guidelines met) and the outcome (stress frequency or self-rated health). In all regression models, those who did not meet any of the guidelines were selected as the reference group.

Proportional odds assumption and goodness of fit for each of the ordinal logistic regression models were assessed using the Brant test [71], Hosmer-Lemeshow test, Lipsitz test, and Pulkstenis-Robinson tests [72]. The regression model with stress frequency as the outcome variable did not violate the proportional odds assumption, and the goodness of fit was acceptable, as indicated by the Brant test $\left(\chi^{2}(69)=-86.68, p=>0.999\right)$, Lipsitz test $(\mathrm{LR}[9]=11.98, p=0.214)$, Hosmer-Lemeshow test $\left(\chi^{2}(35)=32.54, p=0.588\right)$, and PulkstenisRobinson chi-square and deviance tests $\left(\chi^{2}(7289)=7222\right.$, $\left.p=0.709 ; \quad D^{2}(7289)=4272, \quad p>0.999\right)$. Similarly, the Brant test $\left(\chi^{2}(69)=66.84, p=0.551\right)$, Lipsitz test (LR [9] $=4.96, p=0.838)$, Hosmer-Lemeshow test $\left(\chi^{2}(35)=\right.$ 14.59, $p=0.999$ ), and Pulkstenis-Robinson chi-square and deviance tests $\left(\chi^{2}(7505)=7036, \quad p>0.999\right.$; $\left.D^{2}(7505)=3592, p>0.999\right)$ indicated that the regression model with self-rated health quality as the outcome variable did not violate the proportional odds assumption and that the goodness of fit was acceptable.

\section{Results}

\section{Sample characteristics}

The mean ( \pm standard deviation) age of participants was $48 \pm 14$ years. Most participants were females and highly educated, had middle socio-economic status, and lived with their partner (Table 1). The participants' responses on the question about frequency of stress ranged from never to every day, with approximately half of the participants (47\%) reporting occasionally experiencing stress. The participants' responses on the question about selfrated health ranged from very bad to very good, with approximately half of the participants $(55 \%)$ rating their health as good. Only $25 \%$ of participants met all three guidelines, while $7 \%$ of participants did not meet any of the guidelines. Two guidelines were met by $41 \%$, and a single guideline was met by $26 \%$ of participants.

\section{Movement behaviours and stress}

For the participants who only met the guideline for MVPA or for SB, we did not find a statistically significant difference from the reference group (i.e. those who did not meet any of the movement guidelines) in the frequency of stress (Table 2). Those who met the sleep guideline only had approximately two times greater odds of reporting lower frequency of stress, compared with the reference group. Similar associations with lower frequency of stress were found for meeting any two of the guidelines and for meeting the overall, combined guidelines.

In the regression model with the number of guidelines met as an explanatory variable, we found a significant linear trend. The likelihood of higher stress frequency decreased with the number of guidelines met.

\section{Movement behaviours and self-rated health}

For the participants who only met the guideline for SB or for sleep, or for both sleep and SB, we did not find a statistically significant difference from the reference group (i.e. those who did not meet any of the movement guidelines) in self-rated health (Table 3). Those who met the MVPA guideline only had approximately two times greater odds of reporting better health, compared with the reference group. Similar associations with better selfrated health were found for meeting any two of the guidelines, except sleep and SB. Those who met the overall, combined guidelines had approximately three times greater odds of reporting better health, compared with the reference group.

In the regression model with the number of guidelines met as an explanatory variable, we found a significant linear trend. The likelihood of better self-rated health increased with the number of guidelines met.

\section{Discussion}

\section{Main findings}

The results of this study suggest that meeting the sleep guideline only, any combination of two movement behaviour guidelines, or all three movement behaviour 
Table 1 Participant characteristics

\section{Characteristic}

Age group

18 to 44 years

$896(38)$

45 to 64 years

1153 (49)

65 years or more

284 (12)

Female

$1731(74)$

BMI

Underweight or 'normal' $\left(<25 \mathrm{~kg} / \mathrm{m}^{2}\right)$

$1220(52)$

Overweight $\left(25.0-29.9 \mathrm{~kg} / \mathrm{m}^{2}\right)$

811 (35)

Obese $\left(\geq 30 \mathrm{~kg} / \mathrm{m}^{2}\right)$

302 (13)

Smoker

404 (17)

Education

Primary or secondary education

$687(30)$

Higher education

$1646(70)$

Socio-economic status

High or very high

277 (12)

Middle

$1820(78)$

Low or very low

$236(10)$

Living arrangement

Living with partner

1785 (77)

Living without partner

$548(23)$

Place of residence

Urban

1219 (52)

Rural

1114 (48)

Self-rated health

Very good

314 (13)

Good

$1287(55)$

Fair

658 (28)

Bad

68 (3)

Very bad

$6(0.3)$

Experiencing stress

Every day

139 (6)

Often

$689(30)$

Occasionally

1086 (47)

Very rarely

$392(17)$

Never

27 (1)

Meeting guidelines

None

Only for MVPA

$221(9)$

Only for SB

175 (8)

Only for sleep

217 (9)

For SB and MVPA

For sleep and MVPA

370 (16)

For sleep and SB

309 (13)

For sleep, SB, and MVPA

$591(25)$ 
Table 1 Participant characteristics (Continued)

\begin{tabular}{ll}
\hline Characteristic & $\boldsymbol{n}(\%)$ \\
\hline Number of guidelines met & $171(7)$ \\
None & $613(26)$ \\
1 & $958(41)$ \\
2 & $591(25)$ \\
3 &
\end{tabular}

guidelines is associated with less frequent stress. Meeting the MVPA guideline alone or in combination with any other movement behaviour guideline is associated with better self-rated health. We did not find significant associations with stress frequency and self-rated health for meeting the SB guideline only. The likelihood of less frequent stress and better self-rated health increases with the number of guidelines met. These findings highlight the importance of encouraging adults to meet as many movement guidelines as possible, while meeting the sleep guideline seems to be particularly important for coping with stress and meeting the MVPA guideline seems to be particularly important for improving selfrated health.

Table 2 The association between meeting movement guidelines and the frequency of experiencing stress

\begin{tabular}{lll}
\hline & Odds Ratio $[95 \% \mathrm{Cl}]$ & $\boldsymbol{p}$ \\
\hline Guideline(s) met & & \\
None & {$[$ ref $]$} & 0.582 \\
Only for MVPA & $0.90[0.61,1.32]$ & 0.162 \\
Only for SB & $0.75[0.50,1.12]$ & $0.001^{* *}$ \\
Only for sleep & $0.51[0.35,0.75]$ & $0.013^{*}$ \\
For SB and MVPA & $0.63[0.43,0.90]$ & $0.002^{* *}$ \\
For sleep and MVPA & $0.57[0.40,0.81]$ & $<0.001^{* * *}$ \\
For sleep and SB & $0.48[0.33,0.69]$ & $<0.001^{* * *}$ \\
For sleep, SB, and MVPA & $0.45[0.32,0.63]$ & \\
Number of guidelines met & & \\
0 & {$[$ ref $]$} & $0.027^{*}$ \\
1 & $0.69[0.50,0.96]$ & $<0.001^{* * *}$ \\
2 & $0.55[0.40,0.76]$ & $<0.001^{* * *}$ \\
3 & $0.45[0.32,0.62]$ & $<0.001^{* * *}$ \\
Linear trend & & 0.428 \\
Quadratic trend & & \\
\hline
\end{tabular}

Note: $\mathrm{Cl}$ confidence interval; SB sedentary behaviour; MVPA moderate-tovigorous physical activity. The regression models were adjusted for age, sex, body mass index, level of education, socio-economic status, employment status, place of residence (urban / rural), living arrangement (with partner / without partner), smoking status, and self-rated health. ${ }^{*} p<0.05$, ${ }^{* *} p<0.01,{ }^{* * *} p<0.001$

\section{Comparison with previous studies}

Our findings are in accordance with the results of two studies conducted by Oftedal et al. [44, 45], in which the latent class representing a favourable movement behaviour composition (i.e. sufficient MVPA, low SB, and sufficient sleep) was associated with the lowest likelihood of mental distress, compared with the remaining latent classes that represented unfavourable movement behaviour compositions. These comparisons should, however, be taken with caution, because the latent classes in the Oftedal et al. [44, 45] studies were based not only on movement behaviours but also on dietary habits. Furthermore, two other previous studies [46, 47] did not find a significant association between movement behaviours and stress, possibly because of their significantly smaller sample sizes compared to the current study. In

Table 3 The association between meeting movement guidelines and self-rated health

\begin{tabular}{lll}
\hline & Odds Ratio $[95 \% \mathrm{Cl}]$ & $\boldsymbol{p}$ \\
\hline Guideline(s) met & & \\
None & {$[$ ref $]$} & $<0.001^{* * *}$ \\
Only for MVPA & $2.24[1.50,3.36]$ & 0.099 \\
Only for SB & $1.43[0.94,2.19]$ & 0.919 \\
Only for sleep & $1.02[0.68,1.53]$ & $<0.001^{* * *}$ \\
For SB and MVPA & $2.33[1.57,3.44]$ & $0.002^{* *}$ \\
For sleep and MVPA & $1.78[1.23,2.59]$ & 0.100 \\
For sleep and SB & $1.37[0.94,2.00]$ & $<0.001^{* * *}$ \\
For sleep, SB, and MVPA & $2.94[2.07,4.19]$ & \\
Number of guidelines met & & $0.022^{*}$ \\
0 & {$[$ ref $]$} & $0.001^{* *}$ \\
1 & $1.49[1.06,2.10]$ & $<0.001^{* * *}$ \\
2 & $1.76[1.26,2.45]$ & $<0.001^{* * *}$ \\
3 & $2.92[2.05,4.15]$ & 0.599 \\
\hline
\end{tabular}

Note: $C l$ confidence interval; $S B$ sedentary behaviour; MVPA moderate-tovigorous physical activity; $B M I$ body mass index. The regression models were adjusted for age, sex, body mass index, level of education, socio-economic status, employment status, place of residence (urban / rural), living arrangement (with partner / without partner), smoking status, and frequency of stress. ${ }^{*} p<0.05,{ }^{* *} p<0.01,{ }^{* * *} p<0.001$ 
our study, the strength of the association with stress frequency was almost identical across the groups meeting a combination of any two guidelines. It might be that for coping with stress the number of movement behaviour guidelines met matters more than which specific combination of movement guidelines is met.

Within the composition of movement behaviours, MVPA often shows the strongest positive association with mental well-being [73-76]. However, we did not find a significant association between meeting the MVPA guideline and stress frequency. Leisure-time MVPA is often promoted as a strategy to manage stress $[77,78]$. It might be that some individuals in our sample met the MVPA guideline in the attempt to cope with frequent stress. Such cases could have attenuated the inverse association between MVPA and stress frequency in our sample, but this has to be confirmed in future, longitudinal studies.

Our findings regarding self-rated health are in accordance with the results of Oftedal et al. [44] study, in which all three latent classes representing unfavourable movement behaviour compositions had significantly worse self-rated health than the latent class representing a favourable composition of movement behaviours. In the Oftedal et al. [44] study, the poorest self-rated health status was found among those with a combination of low PA, high SB, and inadequate sleep, which is also congruent with the results of our study. As mentioned earlier, these comparisons should be taken with caution, because the latent classes in the Oftedal et al. [44] study were based not only on movement behaviours but also on dietary habits.

Our study showed that meeting the MVPA guideline alone or in a combination with meeting any other movement guideline is associated with better self-rated health, which is in accordance with previous findings. The positive association of MVPA with self-rated health among adults (while considering other movement behaviours) was also found in the von Rosen and Hagströmer [48] study. Similarly, results of the Park et al. [47] study suggested that increasing the time spent in MVPA at the expense of the time spent in SB is associated with better self-rated health in adults. Within the composition of movement behaviours, MVPA often shows the strongest positive association with health $[1,7,42,73]$. The findings in our sample seem to be in line with these findings.

Similar as in our sample of adults, meeting more movement behaviour guidelines was found to be associated with better health and well-being among Australian adolescents [79]. These findings have important implications for health promotion, as they highlight the importance of encouraging adults to meet as many movement behaviour guidelines as possible. Promoting the integrated 24-h movement guidelines might be a feasible way to do it $[12,16-18]$.

\section{Practical implications}

Given the high prevalence of experiencing stress and poor self-rated health in the population, the relatively large reductions in odds of these outcomes associated with meeting the 24-h movement guidelines can be considered practically meaningful from the public health perspective. Public health interventions and strategies encouraging people to engage in $150 \mathrm{~min}$ or more of MVPA per week, sit less than $8 \mathrm{~h}$ per day, and sleep between 7 and $9 \mathrm{~h}$ per day are likely to be good investments in reducing the frequency of stress and improving self-rated health among adults.

\section{Strengths and limitations}

The key strengths of the current study include a large sample size and exploring how meeting recommendations for specific movement behaviours (and all their combinations) is associated with two important health outcomes. Several limitations of the study should also be highlighted. First, the study sample was not fully representative of the general population (for example, in terms of distributions of sexes, education levels, and smoking status), which limits the generalisability of the findings. However, the sample was representative of the Slovenian population in terms of meeting the MVPA guideline, stress, self-rated health, age, BMI, socioeconomic status, place of residence, and living arrangement [80]. Second, given that the data were collected using self-reports, the findings of the study may have been affected by recall errors and social desirability bias. Third, we did not consider guidelines on screen time and muscle-strengthening activity [12]. Also, given that the 24-h movement guidelines for adults do not include specific recommendations for different domains in which MVPA and SB can take place (e.g. work, transport, domestic, leisure time), we did not consider possible differential outcomes of domain-specific activities. Finally, no conclusions about causality could be drawn, because the study was cross-sectional. Studies with longitudinal and experimental designs are warranted to better understand the causal relationships.

\section{Conclusion}

Our results suggest that adults aged 18 years and over who meet the sleep guideline, any combination of two movement behaviour guidelines, or all three movement behaviour guidelines experience stress less frequently, compared with those who do not meet any of the guidelines. Meeting the MVPA guideline alone or in combination with any other movement behaviour guideline is associated with better self-rated health. The likelihood of 
less frequent stress and better self-rated health increases with the number of guidelines met. These findings highlight the public health importance of encouraging adults to meet as many movement behaviour guidelines as possible, while meeting the sleep guideline seems to be particularly important for coping with stress and meeting the MVPA guideline seems to be particularly important for improving self-rated health.

\section{Abbreviations}

BMI: Body mass index; Cl: Confidence interval; DABQ: Daily Activity Behaviours Questionnaire; MVPA: Moderate-to-vigorous physical activity; OR: Odds ratio; SB: Sedentary behaviour; VIRTUE: Viable Integrative Research in Time-Use Epidemiology

\section{Acknowledgements}

The authors gratefully acknowledge the European Commission for funding the InnoRenew CoE project (Grant Agreement \#739574) under the Horizon2020 Widespread-Teaming program and the Republic of Slovenia (Investment funding of the Republic of Slovenia and the European Union of the European Regional Development Fund). The authors also acknowledge the Slovenian Research Agency for funding the infrastructure group at the University of Primorska (research core funding No. 10-0035).

\section{Authors' contributions}

KK and NŠ conceptualised the study. KK processed the data. KK and NK drafted the initial version of the manuscript. DL conceptualised and carried out statistical analysis, and contributed to interpretation of results and drafting the manuscript. ŽP contributed to conceptualising the data analysis, interpretation of results, and drafting the manuscript. SC contributed to drafting the manuscript. All authors reviewed all versions of the manuscript and contributed intellectually to its content.

\section{Funding}

Authors received no funding for the study.

\section{Availability of data and materials}

The datasets used and/or analysed in the current study are available from the corresponding author upon reasonable request.

\section{Declarations}

\section{Ethics approval and consent to participate}

The study protocol was approved by the Republic of Slovenia National Medical Ethics Committee (approval number: 0120-557/2017/4). All participants provided informed consent before enrolling in the study.

\section{Consent for publication}

Not applicable.

\section{Competing interests}

The authors declare that they have no competing interests.

\section{Author details}

${ }^{1}$ University of Primorska, Andrej Marušič Institute, Koper, Slovenia. ${ }^{2}$ InnoRenew CoE, Izola, Slovenia. ${ }^{3}$ Institute for Health and Sport, Victoria University, Melbourne, Australia. ${ }^{4}$ Health Centre Murska Sobota, Murska Sobota, Slovenia. ${ }^{5}$ University of Primorska, Faculty of Health Sciences, Izola, Slovenia.

Received: 9 February 2021 Accepted: 28 April 2021

Published online: 17 May 2021

\section{References}

1. Chastin SF, Palarea-Albaladejo J, Dontje ML, Skelton DA. Combined effects of time spent in physical activity, sedentary behaviors and sleep on obesity and cardio-metabolic health markers: a novel compositional data analysis approach. PLoS One. 2015;10(10):e0139984. https://doi.org/10.1371/journal. pone.0139984
2. Pedišić Ž, Dumuid D, Olds TS. Integrating sleep, sedentary behaviour, and physical activity research in the emerging field of time-use epidemiology: definitions, concepts, statistical methods, theoretical framework, and future directions. Kinesiology. 2017:49(2):252-69.

3. Tremblay MS. Introducing 24-hour movement guidelines for the early years: a new paradigm gaining momentum. J Phys Act Health. 2020;17(1):92-5. https://doi.org/10.1123/jpah.2019-0401.

4. Pedišić Ž. Measurement issues and poor adjustments for physical activity and sleep undermine sedentary behaviour research - the focus should shift to the balance between sleep, sedentary behaviour, standing and activity. Kinesiology. 2014;46(1):135-46.

5. Gupta N, Rasmussen CL, Holtermann A, Mathiassen SE. Time-based data in occupational studies: the whys, the hows, and some remaining challenges in compositional data analysis (CoDA). Ann Work Exposures Health. 2020; 64(8):778-85. https://doi.org/10.1093/annweh/wxaa056.

6. Matricciani L, Bin YS, Lallukka T, Kronholm E, Wake M, Paquet C, et al. Rethinking the sleep-health link. Sleep health. 2018;4(4):339-48. https://doi. org/10.1016/j.sleh.2018.05.004.

7. Rollo S, Antsygina O, Tremblay MS. The whole day matters: understanding 24-hour movement-guideline adherence and relationships with health indicators across the lifespan. J Sport Health Sci. 2020;9(6):493-510. https:// doi.org/10.1016/j.jshs.2020.07.004.

8. Janssen I, Clarke AE, Carson V, Chaput J-P, Giangregorio LM, Kho ME, et al. A systematic review of compositional data analysis studies examining associations between sleep, sedentary behaviour, and physical activity with health outcomes in adults. Appl Physiol Nutr Metabol. 2020;45(Suppl. 2): S248-S57.

9. Tremblay MS, Carson V, Chaput JP, Connor Gorber S, Dinh T, Duggan M, et al. Canadian 24-Hour Movement Guidelines for Children and Youth: An Integration of Physical Activity, Sedentary Behaviour, and Sleep. Appl Physiol Nutr Metabol1. 2016;41(6 Suppl 3):S311-27.

10. Tremblay MS, Chaput JP, Adamo KB, Aubert S, Barnes JD, Choquette L, et al. Canadian 24-hour movement guidelines for the early years (0-4 years): an integration of physical activity, sedentary behaviour, and sleep. BMC Public Health. 2017;17(Suppl 5):874. https://doi.org/10.1186/s12889-017-4859-6.

11. World Health Organisation. Guidelines on physical activity, sedentary behaviour and sleep for children under 5 years of age. Geneva: World Health Organization; 2019. Available from: https://www.who.int/publica tions/i/item/9789241550536. Accessed 18 Dec 2020

12. Ross R, Chaput J-P, Giangregorio LM, Janssen I, Saunders TJ, Kho ME, et al. Canadian 24-Hour Movement Guidelines for Adults aged 18-64 years and Adults aged 65 years or older: an integration of physical activity, sedentary behaviour, and sleep. Appl Physiol Nutr Metabol. 2020;45(Suppl. 2):S57S102.

13. Draper CE, Tomaz SA, Biersteker L, Cook CJ, Couper J, de Milander M, et al. The south African 24-hour movement guidelines for birth to 5 years: an integration of physical activity, sitting behavior, screen time, and sleep. $J$ Phys Act Health. 2020;17(1):109-19. https://doi.org/10.1123/jpah.2019-0187.

14. Australian Government Department of Health. Australian 24-Hour Movement Guidelines for Children and Young People (5-17 years) - An Integration of Physical Activity, Sedentary Behaviour and Sleep. 2019. Available from: https://www1.health.gov.au/internet/main/publishing.nsf/ Content/health-24-hours-phys-act-guidelines. Accessed 18 Dec 2020.

15. Ministry of Health. Sit Less, Move More, Sleep Well: Physical Activity Guidelines for Children and Young People. 2017. Available from: https:// www.health.govt.nz/our-work/preventative-health-wellness/physical-a ctivity\#kids. Accessed 12 Dec 2020.

16. Khamput T, Phuangkrampun M, Sangsumritpol W, Thongbo T, Sianglee S, Kaeyai T. Thailand recommendations on physical activity, non-sedentary lifestyles, and sleeping. 2017. Available from: http://resource.thaihealth.or.th/ library/hot/16254. Accessed 12 Dec 2020.

17. UKK Institute for Health Promotion Research. Aikuisten liikkumisen suositus [Movement recommendations for adults]. Tampere: UKK Institute for Health Promotion Research; 2019. Available from: https://www.ukkinstituutti.fi/ liikkumisensuositus/aikuisten-liikkumisen-suositus. Accessed 12 Dec 2020

18. Jurakić D, Pedišić Ž. Croatian 24-Hour Guidelines for Physical Activity, Sedentary Behaviour, and Sleep: A Proposal Based on a Systematic Review of Literature. Medicus. 2019;28(2):143.

19. Cliff DP, McNeill J, Vella SA, Howard SJ, Santos R, Batterham M, et al Adherence to 24-hour movement guidelines for the early years and associations with social-cognitive development among Australian preschool 
children. BMC Public Health. 2017;17(Suppl 5):857. https://doi.org/10.1186/ s12889-017-4858-7.

20. Guimarães RF, Gilbert J-A, Lemoyne J, Mathieu M-E. Better health indicators of FitSpirit participants meeting 24-h movement guidelines for Canadian children and youth. Health Promotion International; 2020.

21. The American Institute of Stress. What is Stress? 2020. Available from: https://www.stress.org/daily-life. Accessed 18 Dec 2020.

22. Lazarus R, Folkman S. Stress, appraisal, and coping. New York: Springer Publishing Company; 1984.

23. Dimsdale JE. Psychological stress and cardiovascular disease. J Am Coll Cardiol. 2008;51(13):1237-46. https://doi.org/10.1016/j.jacc.2007.12.024.

24. Melchior M, Caspi A, Milne BJ, Danese A, Poulton R, Moffitt TE. Work stress precipitates depression and anxiety in young, working women and men. Psychol Med. 2007;37(8):1119-29. https://doi.org/10.1017/S0033291 707000414.

25. Kivimäki M, Kawachi I. Work stress as a risk factor for cardiovascular disease. Curr Cardiol Rep. 2015;17(9):630. https://doi.org/10.1007/s11886-015-0630-8.

26. McEwen BS. Protective and damaging effects of stress mediators. N Engl J Med. 1998;338(3):171-9. https://doi.org/10.1056/NEJM199801153380307.

27. Schneiderman N, Ironson G, Siegel SD. Stress and health: psychological, behavioral, and biological determinants. Annu Rev Clin Psychol. 2005;1(1): 607-28. https://doi.org/10.1146/annurev.clinpsy.1.102803.144141.

28. Fioranelli M, Bottaccioli AG, Bottaccioli F, Bianchi M, Rovesti M, Roccia MG. Stress and inflammation in coronary artery disease: a review Psychoneuroendocrineimmunology-based. Front Immunol. 2018;9:2031. https://doi.org/10.3389/fimmu.2018.02031.

29. Gallup. 2020 Gallup Global Emotions 2020. Available from: https://www.ga Ilup.com/analytics/324191/gallup-global-emotions-report-2020.aspx. Accessed 20 Dec 2020.

30. Kalmbach DA, Anderson JR, Drake CL. The impact of stress on sleep: pathogenic sleep reactivity as a vulnerability to insomnia and circadian disorders. J Sleep Res. 2018;27(6):e12710. https://doi.org/10.1111/jsr.12710.

31. Medic G, Wille M, Hemels ME. Short- and long-term health consequences of sleep disruption. Nat Sci Sleep. 2017;9:151-61. https://doi.org/10.2147/NSS. S134864.

32. Stults-Kolehmainen MA, Sinha R. The effects of stress on physical activity and exercise. Sports Med. 2014;44(1):81-121.

33. Teychenne M, Stephens LD, Costigan SA, Olstad DL, Stubbs B, Turner Al. The association between sedentary behaviour and indicators of stress: a systematic review. BMC Public Health. 2019;19(1):1357.

34. Jylhä M. What is self-rated health and why does it predict mortality? Towards a unified conceptual model. Soc Sci Med. 2009;69(3):307-16.

35. DeSalvo KB, Bloser N, Reynolds K, He J, Muntner P. Mortality prediction with a single general self-rated health question. A meta-analysis. J Gen Intern Med. 2006;21(3):267-75. https://doi.org/10.1111/j.1525-1497.2005.00291.X.

36. Wu S, Wang R, Zhao Y, Ma X, Wu M, Yan X, et al. The relationship between self-rated health and objective health status: a populationbased study. BMC Public Health. 2013;13(1):320. https://doi.org/10.11 86/1471-2458-13-320.

37. Subramanian SV, Huijts T, Avendano M. Self-reported health assessments in the 2002 world health survey: how do they correlate with education? Bull World Health Organ. 2010;88(2):131-8. https://doi.org/10.2471/BLT.09. 067058.

38. Södergren M, Sundquist J, Johansson SE, Sundquist K. Physical activity, exercise and self-rated health: a population-based study from Sweden. BMC Public Health. 2008;8(1):352. https://doi.org/10.1186/1471-2458-8-352.

39. Wilson JJ, Blackburn NE, O'Reilly R, Kee F, Caserotti P, Tully MA. Association of objective sedentary behaviour and self-rated health in English older adults. BMC Res Notes. 2019;12(1):12. https:/doi.org/10.1186/s13104-019-4050-5.

40. Shankar A, Charumathi S, Kalidindi S. Sleep duration and self-rated health: the national health interview survey 2008. Sleep. 2011;34(9):1173-7. https:// doi.org/10.5665/SLEEP.1232.

41. Wagner DC, Short JL. Longitudinal predictors of self-rated health and mortality in older adults. Prev Chronic Dis. 2014;11:E93.

42. Grgic J, Dumuid D, Bengoechea EG, Shrestha N, Bauman A, Olds T, et al. Health outcomes associated with reallocations of time between sleep, sedentary behaviour, and physical activity: a systematic scoping review of isotemporal substitution studies. Int J Behav Nutr Phys Act. 2018;15(1):69. https://doi.org/10.1186/s12966-018-0691-3.

43. Onodera Y, Kitano N, Kuchiki T, Kai Y, Nagamatsu T, Machida S. Isotemporal substitution of sedentary time with physical activity and its associations with mental health of Japanese office workers. J Phys Fit Sports Med. 2019; 68(4):261-8. https://doi.org/10.7600/jspfsm.68.261.

44. Oftedal S, Kolt GS, Holliday EG, Stamatakis E, Vandelanotte C, Brown WJ, et al. Associations of health-behavior patterns, mental health and self-rated health. Prev Med. 2019;118:295-303. https://doi.org/10.1016/j.ypmed.201 8.11.017.

45. Oftedal S, Vandelanotte C, Duncan MJ. Patterns of diet, physical activity, sitting and sleep are associated with socio-demographic, Behavioural, and health-risk indicators in adults. Int J Environ Res Public Health. 2019;16(13): 2375. https://doi.org/10.3390/ijerph16132375.

46. Curtis RG, Dumuid D, Olds T, Plotnikoff R, Vandelanotte C, Ryan J, et al. The association between time-use behaviors and physical and mental wellbeing in adults: a compositional Isotemporal substitution analysis. J Phys Act Health. 2020;17(2):197-203. https://doi.org/10.1123/jpah.2018-0687.

47. Park S, Park S-Y, Oh G, Yoon EJ, Oh I-H. Association between reallocation behaviors and subjective health and stress in south Korean adults: an Isotemporal substitution model. Int J Environ Res Public Health. 2020;17(7): 2488. https://doi.org/10.3390/ijerph17072488.

48. von Rosen P, Hagströmer M. Excellent self-rated health associated with activities of higher intensities: a compositional data analysis approach. J Phys Act Health. 2019;16(11):1007-13. https://doi.org/10.1123/jpah.20190044

49. University of Primorska. Vprašalnik o spanju, sedenju in telesni dejavnosti [Daily Activity Behaviours Questionnaire]. 2019. Available from: https://hea Ithytimeuse.com/DABQ_SlovenianVersion.pdf. Accessed 20 Dec 2020.

50. Landis JR, Koch GG. The measurement of observer agreement for categorical data. Biometrics. 1977;33(1):159-74. https://doi.org/10.2307/252 9310.

51. Jeriček Klanšček H, Hribar K. Obvladovanje stresa [coping with stress]. In: Vinko M, Kofol Bric T, Korošec A, Tomšič S, Vrdelja M, editors. Kako skrbimo za zdravje? Z zdravjem povezan vedenjski slog prebivalcev Slovenije 2016. Ljubljana: National Institute for Public Health; 2016.

52. Latham K, Peek CW. Self-rated health and morbidity onset among late midlife U.S. adults. J Gerontol B Psychol Sci Soc Sci. 2013;68(1):107-16. https://doi.org/10.1093/geronb/gbs104.

53. Lundberg $\mathrm{O}$, Manderbacka K. Assessing reliability of a measure of self-rated health. Scand J Soc Med. 1996;24(3):218-24. https://doi.org/10.1177/1403494 89602400314

54. Core Team R. R: a language and environment for statistical computing. Vienna: R Foundation for Statistical Computing; 2020.

55. R. Studio Team. RStudio: integrated development environment for R. Boston, MA 2020.

56. Wickham H, François R, Henry L, Müller K. dplyr: A Grammar of Data Manipulation. $R$ package version 1.0.2; 2020

57. Wickham H, Chang W, Henry L, Pedersen TL, Takahashi K, Wilke C, et al. ggplot2: Create Elegant Data Visualisations Using the Grammar of Graphics. R package version 3.3.2. 2019.

58. Firke S, Denney B, Haid C, Knight R, Grosser M, Zadra J. janitor: Simple Tools for Examining and Cleaning Dirty Data. R package version 2.0.1; 2020.

59. Waring E, Quinn M, McNamara A, Rubia EAdl, Zhu H, Lowndes J, et al. skimr: Compact and Flexible Summaries of Data. R package version 2.1.2. 2020.

60. Kassambara A. rstatix: Pipe-Friendly Framework for Basic Statistical Tests. R package version 0.6.0; 2020.

61. Venables WN, Ripley BD. Modern applied statistics with S. Fourth ed. New York: Springer; 2002. https://doi.org/10.1007/978-0-387-21706-2.

62. Schlegel B. brant: Test for Parallel Regression Assumption. R package version 0.3; 2020 .

63. Jay M. generalhoslem: Goodness of Fit Tests for Logistic Regression Models. R package version 1.3.4; 2019.

64. Liangruenrom N, Dumuid D, Craike M, Biddle SJH, Pedišić Z. Trends and correlates of meeting 24-hour movement guidelines: a 15-year study among 167,577 Thai adults. Int J Behav Nutr Phys Act. 2020;17(1):106. https://doi.org/10.1186/s12966-020-01011-9.

65. O'Donoghue G, Perchoux C, Mensah K, Lakerveld J, van der Ploeg H, Bernaards C, et al. A systematic review of correlates of sedentary behaviour in adults aged 18-65 years: a socio-ecological approach. BMC Public Health. 2016;16(1):163. https://doi.org/10.1186/s12889-016-2841-3.

66. Lietz F, Piumatti G, Marinkovic J, Bjegovic-Mikanovic V. Correlates of selfrated health in Southern Europe: evidences from national representative samples in Italy and Serbia. J Public Health (Oxford, England). 2017:39(4): $745-53$. 
67. Kraja F, Kraja B, Cakerri L, Burazeri G. SOCIO-DEMOGRAPHIC AND LIFESTYLE CORRELATES OF SELF-PERCEIVED HEALTH STATUS IN A POPULATION-BASED SAMPLE OF ALBANIAN ADULT MEN AND WOMEN. Mater Sociomed. 2016; 28(3):173-7.

68. Khatib M, Mansbach-Kleinfeld I, Abu-Kaf S, Ifrah A, Sheikh-Muhammad A. Correlates of psychological distress and self-rated health among Palestinian citizens of Israel: findings from the health and environment survey (HESPI). Israel J Health Policy Res. 2021;10(1):3. https://doi.org/10.1186/s13584-02100439-z.

69. Cvetkovski S, Reavley NJ, Jorm AF. The prevalence and correlates of psychological distress in Australian tertiary students compared to their community peers. Aust N Z J Psychiatry. 2012;46(5):457-67. https://doi.org/1 $0.1177 / 0004867411435290$

70. Stubbs B, Veronese N, Vancampfort D, Prina AM, Lin P-Y, Tseng P-T, Evangelou E, Solmi M, Kohler C, Carvalho AF, Koyanagi A Perceived stress and smoking across 41 countries: a global perspective across Europe, Africa, Asia and the Americas Sci Rep 2017;7(1):7597, DOI: https://doi.org/10.1038/ s41598-017-07579-w.

71. Brant R. Assessing proportionality in the proportional odds model for ordinal logistic regression. Biometrics. 1990;46(4):1171-8. https://doi.org/1 $0.2307 / 2532457$.

72. Fagerland MW, Hosmer DW. A goodness-of-fit test for the proportional odds regression model. Stat Med. 2013;32(13):2235-49. https://doi.org/10.1 002/sim.5645.

73. McGregor DE, Carson V, Palarea-Albaladejo J, Dall PM, Tremblay MS, Chastin SFM. Compositional analysis of the associations between 24-h movement Behaviours and health indicators among adults and older adults from the Canadian health measure survey. Int J Environ Res Public Health. 2018;15(8): 1779. https://doi.org/10.3390/ijerph15081779

74. Lee E-Y, Spence JC, Tremblay MS, Carson V. Meeting 24-hour movement guidelines for children and youth and associations with psychological wellbeing among south Korean adolescents. Ment Health Phys Act. 2018;14:6673. https://doi.org/10.1016/j.mhpa.2018.02.001.

75. Hajo S, Reed JL, Hans H, Tulloch HE, Reid RD, Prince SA. Physical activity, sedentary time and sleep and associations with mood states, shift work disorder and absenteeism among nurses: an analysis of the cross-sectional Champlain Nurses' study. PeerJ. 2020;8:e8464. https://doi.org/10.7717/peerj. 8464.

76. Rethorst CD, Moncrieft AE, Gellman MD, Arredondo EM, Buelna C, Castañeda SF, et al. Isotemporal analysis of the Association of Objectively Measured Physical Activity with Depressive Symptoms: results from Hispanic community health study/study of Latinos (HCHS/SOL). J Phys Act Health. 2017;14(9):733-9. https://doi.org/10.1123/jpah.2016-0648.

77. Mayo Clinic. Stress management: stress relief: Mayo Clinic; 2020. Available from: https:/www.mayoclinic.org/healthy-lifestyle/stress-management/ba sics/stress-relief/hlv-20049495. Accessed 21 Nov 2020.

78. The American Institute of Stress. Why Does Exercise Reduce Stress? How Much Do you Need? 2020. Available from: https://www.stress.org/why-doesexercise-reduce-stress-how-much-do-you-need-2. Accessed 21 Nov 2020.

79. Khan A, Lee E-Y, Tremblay MS. Meeting 24-h movement guidelines and associations with health related quality of life of Australian adolescents. J Sci Med Sport. 2020;24(5):468-73. https://doi.org/10.1016/j.jsams.2020.10.017.

80. Vinko M, Kofol Bric T, Korošec A, Tomšič S, Vrdelja M. Kako skrbimo za zdravje? Z zdravjem povezan vedenjski slog prebivalcev Slovenije 2016. Ljubljana: National Institute for Public Health; 2016.

\section{Publisher's Note}

Springer Nature remains neutral with regard to jurisdictional claims in published maps and institutional affiliations.

Ready to submit your research? Choose BMC and benefit from:
- fast, convenient online submission
- thorough peer review by experienced researchers in your field
- rapid publication on acceptance
- support for research data, including large and complex data types
- gold Open Access which fosters wider collaboration and increased citations
- maximum visibility for your research: over 100M website views per year
At BMC, research is always in progress.
Learn more biomedcentral.com/submissions

